\title{
O bruxo solto: recepção crítica da microssérie
} Capitu $^{1}$

\author{
Luiz Antonio Mousinho Magalhães²
}




\section{Resumo}

Palavras-chave

O artigo aborda dados da microssérie Capitu, observando aspectos de sua recepção crítica, com ênfase para a crítica jornalística, além de questões dialógicas relacionadas à estrutura da obra. Nele, damos especial atenção à crítica, mas também observamos outros gêneros jornalísticos que abordaram a circulação do produto audiovisual com enfoque mais informativo. Da mesma forma, estaremos atentos à recorrência nos textos do debate em torno da audiência e comunicabilidade da obra, bem como sobre a relação do audiovisual com o texto-fonte.

Ficção televisual, recepção crítica, comunicação.

\section{Abstract}

The present article discusses data from the mini-series Capitu, observing aspects regarding its critical reception, and emphasizing both journalistic criticism and dialogical issues related to the structure of the work. While we afford close attention to criticism, we also observe other journalistic genres that have addressed the circulation of this audiovisual product employing a more informative approach. We will similarly be attentive to the recurrent debate in the texts concerning both the audience and the communicability of the production, as well as the relationship between the audio-visual version and the source text.

\section{Keywords}

Television fiction, critical reception, communication. 
Procurando pensar o circuito de produção, recepção e interações no livro A sociedade enfrenta a sua mídia, José Luiz Braga assinala que a sociedade ao lado "de seus processos de 'produção', sempre gerou também procedimentos críticos e interpretativos que, metalinguisticamente, 'falam' de seus processos materiais expressivos e das interações sociais que vão sendo tecidas em torno destes". Braga chama a atenção para o fato de que as interações sociais em torno do livro (e das artes tradicionais) costumam atingir níveis de excelência, ao contrário do que ocorre no trato crítico sobre a mídia contemporânea. Para ele, essa crítica estaria "muito voltada para a observação dos efeitos sociais do meio", não se preocupando "muito com as estruturas específicas deste ou daquele produto" (BRAGA, 2006, p. 58).

O autor assinala, assim, a existência de um componente de "interação midiática social ampla" em relação ao livro e à arte tradicional, uma situação "lacunar" em relação ao rádio e à TV e intermediária em relação ao cinema ("com fortuna crítica de excelente nível"). Ele defende ainda que um "dos possíveis estimuladores da interação social ampla em torno do livro, do teatro e do cinema é o fato de que a crítica debate não só o 'meio' e seus processos em termos abstratos e gerais, mas sobretudo analisa, comenta e interpreta (inteligentemente) os seus produtos específicos, relacionados a sua formulação, seus objetivos e suas incidências sobre o público usuário" (BRAGA, 2002, p. 61).

Refletindo sobre a obra de Mikhail Bakhtin e seu conceito de dialogismo, Robert Stam assinala como os textos artísticos dialogam com outros textos e também com seus públicos. Stam lembra ainda que qualquer texto "constitui uma forma de ação calculada para leitura ativa e respostas internas, e para reação (...) por parte de críticos, e pastiche ou paródia por outros autores" (STAM, 1992, p. 34).

Discutiremos nesse texto a microssérie Capitu, observando aspectos de sua recepção crítica e dos vários diálogos que constituem texto audiovisual e recepção. Recepção traduzida em formatos jornalísticos, com especial atenção à crítica, mas também analisando dados de gêneros e formatos jornalísticos 
mais informativos e que abordaram a circulação do produto audiovisual em foco. Em se tratando de obra do cineasta e diretor de TV Luiz Fernando Carvalho, encarado como um autor no audiovisual, a presença crítica propriamente dita parece estar mais presente do que o comum em relação a produtos televisivos, bem como a cobertura jornalística parece ser mais ampla, apresentando alguns contornos de discurso crítico.

Selecionamos um corpus de onze textos publicados em revistas e jornais brasileiros, incluindo os de maior circulação, como os jornais Folha e O Estado de S. Paulo, O Globo, Correio Brasiliense e as revistas Isto é e Veja. Podemos dividir os textos em três blocos, de modo que, no primeiro, estaria um grupo de quatro artigos de crítica jornalística propriamente dita; um segundo bloco com três textos que trazem elementos dos gêneros jornalísticos entrevista e reportagem, mantendo ainda feição crítica; e, em um terceiro bloco, reunimos quatro textos em que predomina o discurso informativo.

No primeiro bloco de textos, vemos uma forte aproximação à crítica cinematográfica, inclusive pelo fato de alguns dos autores serem críticos de cinema. As relações entre a microssérie e o texto fonte, o romance machadiano, são debatidas com fortes referências também às relações entre literatura e sociedade, no rastro do que já foi vastamente investigado pela crítica literária acadêmica, mas sem trazer referências a esta (e não insinuo aqui que se deveria trazer).

As atualizações do audiovisual, em termos de trilha sonora e dos muitos intertextos cinematográficos, são apontadas em vários elementos estruturais da obra, como fotografia, figurino, trabalho com o espaço narrativo etc. Referências ao expressionismo alemão, ao cinema de Fellini, Luchino Visconti, Truffaut e a outras obras de Carvalho são detalhadas pelos críticos geralmente em clave positiva. Aspectos do tratamento audiovisual são discutidos em sua efetividade estética e como adaptação bem sucedida.

O artigo Ah, esses olhos, de Isabela Boscov, publicado na Veja e identificado na revista como crítica televisiva, traz no subtítulo a afirmação de que "a minissérie 
quebra convenções para traduzir a obra-prima de Machado de Assis". O texto inicia reivindicando a carência do arranjo de "formas e temas" que correspondam à veia machadiana nas muitas adaptações de sua obra e a ambição da microssérie em contemplar esse déficit estético (BOSCOV, 2014, p. 1).

Isabela Boscov aponta a reprodução quase integral do texto de Dom Casmurro e qualifica como "audaciosa" e livre a encenação no galpão das locações, com riscos no chão e objetos que transitam construindo as relações espaciais. Sobre os figurinos, os define como "versão expressionista de figurinos da segunda metade do século XIX". A autora destaca a trilha sonora com sua mistura de música erudita, "mas também rock pesado e folk", e lembra que as ruas não "estão maquiadas", ou seja, traços do contemporâneo como pichações e afins estão aparentes em cena.

Boscov fala na possibilidade de as opções narrativas e de encenação serem percebidas de saída como de um barroquismo excessivo, mas as defende, afirmando que a opção ortodoxa numa produção de época poderia dar um ar antiquado "àquilo que continua vivo e novo". O texto segue discutindo o romance machadiano e seu contexto, relacionando-o com as questões de adaptação adotadas por Luiz Fernando Carvalho e indicando, como maior êxito da microssérie, o "fazer com que as imagens respeitem a margem de dúvidas guardada nas palavras". Apostando assim na efetividade da tradução da equivocidade do texto machadiano, Isabela Boscov identifica no produto televisivo o traço constituinte do texto-fonte, indagando, ao final: "como exigir de um narrador enfeitiçado, afinal, que ele seja lúcido?" (BOSCOV, 2014, p. 3).

O jornal O Estado de S. Paulo publicou pelo menos três artigos sobre a microssérie. O de Luiz Zanin Oricchio comenta Capitu na ocasião de lançamento do DVD e ressalta a concepção de Carvalho de adaptação como invenção (ORICCHIO, 2014, p. 1). Zanin aponta dados do texto e contextos machadianos e propõe ainda que a versão televisiva "exacerba o aspecto operístico". Percebe também "certo barroquismo no sentido de uma estética do exagero, que sugere um diálogo com Fellini" e aponta esta como uma das inúmeras referências 
mobilizadas na construção audiovisual de Capitu. O expressionismo alemão, o Lars Von Trier de Dogville e Luchino Visconti são outras influências lembradas, mas com a ressalva de que "a montagem desse dispositivo jamais cai no artificialismo nem cria uma distância intransponível para o espectador". E aqui Zanin toca não só nas questões de unidade e economia narrativa, mas traz o aspecto da opção pela comunicabilidade com o grande público. Opção que poderíamos pensar aqui operando em sistema com o desvio da opção pela representação realista-naturalista dominante da telenovela e do cinema narrativo. Ao final, o crítico indica aspecto recorrente nas abordagens jornalísticas da microssérie, ou seja, a relação com o texto-fonte, e assinala que Luiz Fernando de Carvalho atingiu em Capitu uma "fidelidade transfigurada", afirmando ainda que a microssérie trouxe "um momento excepcional na medíocre programação da TV brasileira" (ORICCHIO, 2014, p. 3).

Escrevendo também para o Estadão, Beatriz Resende assinala a imposição de Machado aos jovens como uma das "obsessões pedagógicas" que assolam o país, lembrando que Machado não escreveu para os jovens. Chamando a minissérie de "pequena obra prima de um mundo feito de textos e imagens", destaca a caracterização de Dom Casmurro: "o cansado Bento Santiago, num trem contemporâneo, devidamente pichado, surge na pele de um Michel Melamed tornado uma espécie de clown, deformado, ágil, por vezes cômico, por vezes trágico" (RESENDE, 2014, p. 2). Relembrando as intrusões do narrador de Machado e os títulos dos micro-capítulos do livro transformados nas cartelas do audiovisual, Beatriz Resende evoca o leitor contaminado pelo efeito de distanciamento de Brecht e indica que "não é nem o entusiasmo hipnótico nem a catarse paralisante que o espetáculo audiovisual quer provocar" - e aqui vemos novamente o ressaltar o desvio do modelo de representação dominante na TV e o cuidado com a comunicabilidade da obra (RESENDE, 2014, p. 3).

Como terceiro artigo publicado n'O Estado de S. Paulo do corpus aqui analisado, o texto de Luiz Carlos Merten inicia discutindo a questão do adultério, a condição de Bento Santiago como "um homem torturado pelas aparências" 
(MERTEN, 2014, p. 1). Caracteriza a obra audiovisual como uma "ópera-rock" que muitas vezes "desconcerta pelo que tem de excessivo". Refere-se a Michel Melamed como "magnífico" e alude à caracterização de Dom Casmurro como "um clown patético, voyeur caligaresco do próprio passado, que sorve, mais do que espia, aquele beijo que, quando jovem, deu em Capitu".

Merten, como Zanin, assemelha o trabalho de Carvalho ao cinema de Luchino Visconti, a quem chama de "o mais clássico dos cineastas revolucionários", ressaltando no diretor brasileiro a atenção ao detalhe a à beleza visual. Ao lado disso, surge a ressalva de que talvez "não necessitasse tanto filmar através de rendas e brocados para caprichar na imagem" (MERTEN, 2014, p. 2).

$\mathrm{Na}$ "ciranda final de Bentinho e seus mortos", cena na qual o personagem encarna no figurino, nas falas e no gestual as pessoas que passaram pela sua vida, vê ali algo de Jules e Jim de Truffaut. As narrativas seriam assim "fundamentalmente sobre cinzas, sobre fantasmas, sobre as coisas que desapareceram e permanecem vivas na lembrança e as que ainda estão vivas mas que já vão desaparecendo no imaginário" (MERTEN, 2014, p. 3).

Se os quatro textos abordados aqui, o da Veja e os do Estadão, são críticas propriamente ditas, os três que vamos examinar como componentes do que consideramos um segundo bloco constituem-se de um misto de entrevista (como gênero), reportagem e crítica jornalística. Processos de produção e atuação dos personagens (tanto no que se refere aos fictícios, quanto aos atores) estão no centro das atenções. Os textos foram publicados na revista Isto É, na Folha de S. Paulo e no Correio Brasiliense. Esse segundo bloco de textos traz então reportagens, entrevistas e algumas entradas críticas, tendo em comum, em relação aos textos propriamente críticos, a presença de várias falas de Luiz Fernando de Carvalho, embora em número bem mais extenso (o que, no caso do gênero entrevista, é de fato óbvio, ainda que neste haja também dados de avaliação crítica, na cabeça da matéria ou na intenção das perguntas). As falas do entrevistado produzem leitura de vários aspectos da obra, normalmente ratificadas pelos textos jornalísticos. Aqui também se ampliam dados de 
produção, escolha de atores, questões de orçamento. Em vários momentos, expressões no campo semântico do requinte, do luxo e do significativamente bem cuidado são aludidas para fazer referência à microssérie, em relação à qual podemos ler palavras como "artesanato", "esmero".

Pensando a abordagem crítica de TV, José Luiz Braga percebe dois aspectos centrais. O primeiro diz respeito à atenção ao que chama de "processos produtivos", com a exposição de "aspectos anteriores ao que acontece na tela" (BRAGA, 2006, p. 260), como dados do negócio, das atividades e processos de produção e criação, o que parece se configurar aqui. A segunda tônica, conforme o autor, seria atada a uma atenção dada ao "comportamento": "o que parece fascinar os jornalistas e comentadores em geral é o 'comportamento humano' (...) é o comportamento dos personagens, dos apresentadores e em geral das personalidades televisuais (mesmo os jornalistas)" (BRAGA, 2006, p. 261). Braga assinala ainda que os personagens ficcionais são discutidos "na lógica dos comportamentos humanos e não na lógica das estruturas dramáticas". O autor anota ainda que, ao se falar dos personagens, em seguida costuma-se resvalar para a observação do comportamento de atores e atrizes.

O texto da Isto É, assinado por Francisco Alves Filho, coloca-se como anúncio da microssérie que irá ao ar e destaca as "imagens luxuosas e sofisticadas" que se tornaram "marca registrada de Carvalho". A matéria toma depoimento de Melamed, em que o ator comenta o clima no set de gravação, qualificando-o como "um congresso de magos e ilusionistas", destacando ainda o tom operístico da obra, indicando os resultados positivos da escolha das locações no prédio em ruínas do Automóvel Clube, após informar o peso dos problemas de orçamento na escolha. A abordagem de Carvalho resulta, para o jornalista, no seu "conhecido esmero" na direção de atores, ao lado de um trabalho cuidadoso com figurinos, cenários e iluminação.

O texto de Sylvia Colombo, da Folha de S. Paulo, é pontilhado por depoimentos do diretor, trazidos em meio a informes referenciais sobre produção e veiculação da microssérie e investidas da autora em termos de leitura da 
obra. Segundo Colombo, as "imagens (...) surpreendem pela beleza e pela transformação do espaço. Um mesmo local corresponde a cantos diferentes da memória de um velho (...) que narra a própria desgraça e se mostra incapaz de resgatar o passado a partir das sombras de lembranças que vê desfazerem-se nas paredes de um antigo salão" (COLOMBO, 2014, p. 2). Colombo destaca o estado do lugar escolhido para as locações e uma fala do diretor sobre como conseguiu extrair maior felicidade estética da situação decadente do lugar: "Tudo ali é ruína. Um lugar perfeito para contar a história de um homem em ruínas, que não consegue resgatar o que perdeu".

Um terceiro texto que tomamos nessa linha mais informativa é assinado por Sérgio Maggio, do Correio Brasiliense. Trata-se de uma entrevista - enquanto gênero jornalístico, introduzida por uma cabeça de texto de dois parágrafos. Nela, o autor da matéria aponta Carvalho como "criador único", faz referências à "mão autoral" do diretor e o caráter "artesanal" de sua obra, bem como a forma "requintada" do projeto Quadrante. O trabalho de Carvalho é ainda apanhado como incomum e atípico quanto ao que o jornalista chama de "padrão vencido da teledramaturgia brasileira" (MAGGIO, 2013, p. 1).

Na entrevista, Carvalho aponta Capitu como "um ensaio sobre a dúvida". E diz que, rastreando os dados da passagem do tempo e o discurso sobre a modernidade de um Brasil que convivia com a escravidão, tentou traduzir no audiovisual um sentido de "finitude das coisas". Assim, "Dom Casmurro (...) está incorporado ao trágico (...) a um tempo e a um espaço que não voltarão jamais" E mais:

Ele vive a história, se emociona com a história, mas, simultaneamente, na frase seguinte, é capaz de se afastar e traçar um desenho (...) sobre a realidade amorosa, o tempo e seu estado atual: 'vivo bem, como bem, não durmo mal...' - e, no canto do olho, talvez uma lágrima esteja escorrendo (MAGGIO, 2013, p. 2).

Tratando das relações de diálogo com o texto-fonte, o diretor ratifica sua noção de adaptação e reafirma ser contrário a alterar enredo, injetar 
personagens, diálogos, tramas paralelas, final diferente etc. Ou seja, posiciona-se contrariamente ao que, nas adaptações de obras literárias, é chamado de adição, isto é, ao acrescimento de elementos que não estão no texto literário, procedimento que representa uma das possibilidades de diálogo com o texto fonte, assim como os de redução, deslocamento, transformação, simplificação, ampliação etc. (BRITO, 2006, p. 20).

Na mesma entrevista, Carvalho ressalta mais uma vez que cada palavra e vírgula da microssérie saíram das páginas de Machado de Assis. Se pensarmos esse cuidado de aproximação com o texto em paralelo com as inovações traduzidas, por exemplo, no uso dos anacronismos, podemos remeter à noção de fidelidade proposta por André Bazin no seu famoso ensaio Por um cinema impuro - defesa da adaptação. No texto, o autor assinala, que "a boa adaptação deve conseguir restituir o essencial do texto e do espírito" do texto (BAZIN, 1991, p.96), dando exemplos de mudanças substanciais e de permanências essenciais que, no todo, produzem essa fidelidade transfigurada.

Em duas perguntas, o jornalista Sérgio Maggio pressiona o diretor sobre problemas de transposição e comunicabilidade na adaptação do romance $A$ Pedra do Reino, que resultou em uma microssérie anterior. Carvalho responde dizendo que fez, nos dois programas, o mesmo esforço de comunicação. Afirma ter ainda "as costas cheias de cicatrizes" por ter feito A Pedro do Reino e, laconicamente, encerra dizendo que, como "qualquer ser humano, às vezes o que produzimos reencontra a vida, outras nem tanto" (MAGGIO, 2013, p. 5).

No terceiro bloco de textos sobre a microssérie Capitu que compõem nosso corpus, selecionamos uma notícia e três reportagens, todas veiculadas em O Globo, uma delas no encarte Revista da TV. Há ainda um quinto texto, que, na verdade, é uma versão ligeiramente ampliada da matéria de $O$ Globo, publicada no Diário do Nordeste. Nele, vemos a presença forte da questão da relação dos jovens com a literatura de Machado de Assis e o possível impacto do programa nas escolas. Na verdade, o tema atravessa os vários conjuntos de textos. Mas, nesse terceiro grupo, a atenção vai para os atores, para a seleção de 
elenco à qual se submeteram, para outras passagens de sua carreira e sua vida pessoal. Os depoimentos do diretor também são bastante utilizados, mas em chave interpretativa. Os custos de produção, os índices de audiência na estreia e a preparação de atores também seguem na pauta, assim como o ludismo do programa, seu tom "pop" e a audiência média (FONSECA, 2014).

A primeira matéria, sem assinatura, é uma notícia de dois parágrafos, publicada em 26 de novembro, dando conta dos dezessete pontos de audiência conseguidos no primeiro dia, o que garantiu a liderança na audiência, um ponto à frente da Record e dez à frente do SBT. A segunda matéria selecionada de O Globo, intitulada Obra-prima de Machado volta modernizada na microssérie Capitu, assinada por Rodrigo Fonseca, trata da trilha sonora e inclui depoimentos de Luiz Fernando Carvalho falando em sua oferta de reconciliação de Machado com os jovens e uma alusão às micro-narrativas e intertítulos que remetem ao cinema mudo e fariam de Dom Casmurro uma trama de colagem afinada ao gosto dos jovens acostumados à interatividade (FONSECA, 2014, p.2). A matéria também reproduz entrevista com o professor de literatura Diogo Mendes, que celebra a microssérie pelo interesse que desperta nos alunos (FONSECA, 2014, p.4). A matéria destaca que o professor assistiu ao programa com antecedência, a convite do jornal, e nela Rodrigo Fonseca afirma ainda que a microssérie "faz mídia e cultura comungarem sem hermetismos" e que, ao "ultrapassar a questão do adultério, Carvalho explora de forma poética como Bentinho é a alegoria da maneira com a qual uma ideia fixa pode auto-anular alguém" (FONSECA, 2014, p. 5). A matéria conclui com uma fala de Carvalho dizendo ser necessário lidar com a juventude da obra de Dom Casmurro e retirar o escritor do pedestal da Academia, "deixando o Bruxo solto", numa alusão ao famoso epíteto Bruxo do Cosme Velho, usado nas referências a Machado, e o "solto", ao que nos parece, uma maneira feliz de sintetizar as atualizações trabalhadas em nova mídia para o texto- fonte.

A minissérie também é destaque na Revista da TV, em matéria assinada por Zean Bravo. Destaca basicamente os processos de produção e os 
personagens nos dois sentidos da expressão apontados por José Luiz Braga, ou seja, personagens ficcionais e pessoas ligadas à produção, sobretudo atores. Assim, escolha e papel de Letícia Persiles e César Cardadeiro são detalhados e os atores são entrevistados para falar da experiência.

Renato Pucci, estudando a recepção da microssérie, rastreia esquemas cognitivos ativados pela recepção e estruturas narrativas movimentadas pela série, no momento em que indaga sobre os consideráveis níveis de audiência alcançados pelo programa, apesar dos vários dados de elementos inusitados na estrutura do audiovisual. Observando os vários mecanismos presentes em Capitu, o autor ressalta ser

razoável supor que essa composição deveria provocar estranhamento nos telespectadores, supostamente habituados apenas à linearidade temporal típica de narrativas clássicas, como as das telenovelas e minisséries. Em combinação com outros aspectos (como as intrusões da narração, as distorções de imagem e os microcapítulos ao estilo machadiano), a audiência de Capitu poderia ter chegado a um traço do Ibope, o que esteve longe de acontecer (PUCCI, 2014, p. 1).

Anacronismos, intrusões do narrador, convivência na tela de personagens e realizadores, o olhar para a câmera como interpelação ao espectador, o fator fake em cena, a presença de inserts de filmes antigos, o congelamento da imagem de personagens e a representação de animais por bonecos, além de dados de metaficção em geral, são as ocorrências de elementos de estranhamento citadas por Pucci. O autor, ao mesmo tempo, resgata momentos da TV brasileira, sobretudo da Globo, emissora em que tais desvios dos modos narrativos clássicos estiveram presentes. Ele repara, nessas ocorrências, a instauração de um ambiente que desenhou a comunicabilidade com o público, além de defender que a microssérie aponta propostas de dramaturgia indicadas nesses antecedentes televisivos.

O rastreamento e reflexões de Pucci indicam ainda, de maneira atenta, o que Capitu traz da tradição da TV e, diríamos aqui, como traços dialógicos. Traços estes que ousam investir em momentos de esgarçamento estético, de 
certa opacidade comunicativa que, como nos melhores momentos de nossa da canção popular, são capazes de apostar em vários níveis de sinais e alcançar a atenção e o desejo do público, numa trama entre produção, indústria e recepção que gerou tantas experiências estimulantes de pregnância estética e comunicabilidade efetiva.

Ao mesmo tempo, lembraríamos como Capitu se filia a uma série de produtos e inovações narrativas nas quais a emissora costuma apostar em momentos pontuais, seja para tentar novas possibilidades de renovação da audiência, seja para vincar sua posição, fincando-se como marca de prestígio. Tal viés de prestígio não só entra no marketing da Globo, como termina respondendo a tensões políticas e estéticas, vindas de setores da sociedade e do Estado, a partir de grupos de pressão e situações de debate que, com alguma frequência, questionam o baixo nível educacional e de outras ordens das TVs comerciais, que são concessões públicas.

Retomando o texto de Renato Pucci Jr, vale também notar quando o autor aponta o quanto Hollywood serviu como um dos modelos da emissora e o quanto a própria Hollywood, desde os anos 1920, absorve influências de narrativas de matrizes que Ihe são estranhas, distantes da narrativa clássica, "mas sempre a serviço dos próprios objetivos, ou seja, sem perder a comunicação com o grande público, sem afrontar demais as suas expectativas" (PUCCI, 2014, p. 16). No caso específico da Globo, poderíamos lembrar que a emissora abrigou, ao longo de sua história e especificamente durante os 21 anos de ditadura militar, autores que Ihe eram heterogêneos estética e ideologicamente ("os meus comunistas", na famosa expressão de Roberto Marinho).

Poderíamos pensar em várias explicações complementares para o bom nível de comunicação com o grande público, com o uso de objetos para representar animais podendo ser tomado como análogo às representações sociais em brincadeiras infantis. Ou seja, uma certa semelhança com essa experiência teatral, por vezes doméstica, por vezes escolar, que dispara uma sensação de familiaridade vinda a par com a estranheza em relação à representação televisiva 
comum, mas que não chega a barrar a comunicação pelo lastro reconhecível apontado, mesclado ao elemento estranho - e vale lembrar que o estranho, para Freud, é algo antes familiar que se torna recalcado (FREUD, 1976).

Podemos pensar ainda na proposta textual de um projeto que incorpora o lírico e o faz de maneira sedutora nas cenas de amor juvenil, na construção desse retrato do amor quando jovem desenhado em atuação, cenário onírico, canção envolvente e trazendo algo da linguagem do videoclipe etc. Além disso, os esquemas cognitivos em termos de memória de longa duração (PUCCI, 2014) poderiam se verificar nas estruturas narrativas do romance machadiano e sua espraiada sedimentação na cultura brasileira, dado de explicação extra-ambiente televisivo, mas também intra-televisivo e fílmico, tendo em vista as várias adaptações de Machado e de obras que, formal ou tematicamente, beberam em suas fontes.

Observando a microssérie televisiva e as conversas por ela provocadas, na maneira como afeta as pessoas pelo fascínio ou pelo tédio, podemos observar como Capitu apanha de maneira tesa a relação de classes entre duas famílias, caracterizadas, por exemplo, nos não-ditos, nos momentos do pai de Capitu visto entre o afeto e os interesses, nas estratégicas do agregado José Dias. Esse dar a ver do contexto social e suas repercussões no contemporâneo vem em um constructo audiovisual que soube atualizar seus elementos, trazendo o melhor da ficção literária e de suas possibilidades de expressar, de construir a vida por meio da ficção. Como assinala Robert Stam, "cada lente, ao revelar aspectos do texto fonte em questão, também revela algo sobre os discursos existentes no momento da reacentuação" (STAM, 2006, p. 48). Ismail Xavier, por sua vez, anota que é de se "esperar que a adaptação dialogue não só com o texto de origem, mas com o seu próprio contexto" (XAVIER, 2003, p. 62).

Na memória do espectador, enredado na minissérie, pode ficar a lembrança tremenda do personagem-ruína não mais Bentinho, não mais Bento Santiago, mas já aprisionado em seu momento Dom Casmurro, visto em co-presença em 
cena com Bentinho, o infante apaixonado, e quase tocando em corpo a delicadeza perdida, desenhando no ar de maneira patética esse gesto impossível ${ }^{3}$.

Por parte do diretor, parece haver consciência de seu espaço de nicho na produção televisiva e de saber se vender enquanto tal. Na recepção jornalística, há certa redundância respeitosa quanto a essa posição. Nessa cobertura jornalística, a sofisticação técnico-estética ou estético-visual é tomada como um valor de mercado a ser levado em conta "de saída", ponto de partida e solo seguro para a avaliação. De toda forma, na pequena e nas muitas entrevistas editadas nos gêneros jornalísticos em torno da microssérie, inclusive na crítica, vê-se um diretor de cinema e TV que muito rejeita e quer, tanto no plano da expressão, como no da comunicação com o telespectador. E podemos concordar com Luiz Carlos Merten, quando ele diz que, com Capitu, "nunca Luiz Fernando de Carvalho foi mais belo" (MERTEN, 2014, p. 3).

Na cobertura mais propriamente informativa do que crítica da microssérie Capitu, o diretor Luiz Fernando de Carvalho é tratado como celebridade, mas ainda aí se vê o esforço e o investimento em discutir a obra em suas propostas estéticas. Obviamente, em alguns momentos, há clara intenção de investimento no aspecto promocional do programa de TV (evidente, por exemplo, no caso do veículo é $O$ Globo), mas, ainda assim, há a intenção de discuti-lo como proposta "diferenciada", mesmo que esteja aí a aposta em um valor de mercado, o rótulo cult com todas as suas veleidades de reforço da imagem de um produto de nicho e signo de prestígio. Tal ressaltar e legitimar o dado do prestígio, no caso, não estaria apenas no "fazer propaganda" da minissérie, mas também no justificar e valorizar o debate jornalístico em torno da microssérie, o "requinte" dos suplementos e cadernos especiais em trazer informação e discussão sobre um produto diferenciado, sendo esse jornalismo mesmo um nicho, um produto segmentado, para públicos atentos a essas marcas de distinção. 
As abordagens jornalísticas, em seus momentos de crítica, aproximam-se dos avanços da crítica de cinema, nos termos apontados por Braga, ao analisar e interpretar produtos específicos e seu ambiente de produção e recepção. Os textos informativos, predominantes quantitativamente, também alcançam algo disso, mas em alguns momentos se limitam à descrição repetitiva dos processos de produção e esquecem as estruturas narrativas, tratando personagens como se não fossem "seres de papel", para usar a expressão de Roland Barthes (BARTHES, 1971, p. 48), além de investirem demais na vida supostamente fascinante das celebridades.

Nas críticas, percebe-se um diálogo com visadas teórico-críticas sobre a obra de Machado, em uma espécie de leitura coletiva sedimentada nas várias reavaliações e suplementações recebidas pela obra do autor, vindas mesmo dos estudos e ensaios acadêmicos. Aqui, também em relação a textos críticos e analíticos, podemos perceber "os ecos e reverberações de outros enunciados", assinalados por Mikhail Bakhtin e recuperados por Robert Stam, em sua vigorosa aclimatação do conceito de dialogismo para o ambiente da teoria do cinema e da crítica da cultura (STAM, 1992, p.75).

Notamos nos textos, também, certo fascínio pelo risco assumido pela microssérie em instaurar um ruído de comunicação na média da programação televisiva e, ao mesmo tempo, pelo bom nível de comunicabilidade atingida; pela proeza em conseguir o equilíbrio entre esses dois planos. Ao mesmo tempo, pode ser ressaltado igualmente, nos textos, o perceber os personagens nas estruturas dramáticas, sem investir tanto na questão das celebridades.

Em suma, pudemos observar, nos textos abordados, a presença de uma crítica atenta a outras experiências e a um público ambientado a uma TV comercial que vem experimentando, mesmo que de maneira pontual, aspectos de outras experiências narrativas, para além da rotina automatizada, talvez até como sua condição de sobrevivência. Por fim, devemos acrescentar que a recepção pelo público e pela crítica pode ser muito mais vigorosa do que, muitas vezes, pressupomos. 


\section{Referências}

BAZIN, A. "Por um cinema impuro - defesa da adaptação". In: O que é cinema. São Paulo: Brasiliense, 1991.

BARTHES, R. O grau zero da escritura. São Paulo: Cultrix, 1971.

BORGES, G. et al. "Televisão: Formas Audiovisuais de Ficção e de Documentário". In: Seminário Televisão: Formas Audiovisuais de Ficção e Documentário Sociedade Brasileira de Cinema e Audiovisual, v. 2, 2012, Campinas. Campinas: Faro, Socine, 2012. Disponível em: http://www.socine.org.br/livro/televisoes. pdf. Acesso em: 18 dez. 2014.

BOSCOV, I. "Ah, esses olhos...". Revista Veja, São Paulo, dez. 2008. Disponível em: http://veja.abril.com.br/101208/p_192.shtml. Acesso em: dez. 2014.

BRAGA, J. L. A sociedade enfrenta sua mídia. São Paulo: Paulus, 2006.

BRAVO, Z. "Atores jovens são aposta de Luiz Fernando de Carvalho em Capitu". O Globo, Rio de Janeiro, nov. 2008. Disponível em http://oglobo.globo.com/ cultura/revista-da-tv/atores-jovens-sao-apostas-do-diretor-luiz-fernandocarvalho-em-capitu-3604567. Acesso em: 19 de dez. 2014.

BRITO, J. B. de. Literatura e cinema: narrativas em conflito. São Paulo: Unimarco, 2005. Disponível em: http://imagensamadasdotcom.files.wordpress. com/2011/04/literatura_no_cinema.pdf. Acesso em 22 set. 2014.

COlOMBO, S. "Hoje é dia de Capitu". Folha de São Paulo, São Paulo, nov. 2008. Disponível em: http://www1.folha.uol.com.br/fsp/ilustrad/fq2211200807.htm. Acesso em: 19 dez. 2014. 
FILHO, F. A. "Capitu é um luxo". Revista Isto é, São Paulo, dez. 2008. Disponível em: http:// www.istoe.com.br/reportagens/948_CAPIU+E+UM+LUXO. Acesso em: 19 dez. 2014.

FONSECA, R. "Bruxo também é pop". Diário do Nordeste, dez. 2008. Disponível em: http://diariodonordeste.verdesmares.com.br/cadernos/zoeira/bruxo-tambem-epop-1.516759. Acesso em: 19 dez. 2014.

FONSECA, R. "Obra-prima de Machado de Assis volta modernizada na microssérie Capitu". O Globo, Rio de Janeiro, dez. 2008. Disponível em: http://oglobo. globo.com/cultura/revista-da-tv/obra-prima-de-machado-de-assis-voltamodernizada-na-microsserie-capitu-3603811. Acesso em: 19 dez. 2014.

FREUD, S. "O estranho". In: Uma Neurose Infantil e outros trabalhos. Rio de Janeiro: Imago, 1976.

MAGGIO, S. "Luiz Fernando Carvalho lança sua visão estética sobre o romance Dom Casmurro". Correio Braziliense, Brasília, ago. 2008. Disponível em http://divirta-se. correioweb.com.br/materias.htm?materia=5497. Acesso em: 9 jan. 2013.

MENEGUINI, C. "Minissérie 'Capitu' vai apresentar 'Angelina Jolie' brasileira". O Globo, Rio de Janeiro, nov. 2008 Disponível em: http://g1.globo.com/Noticias/ PopArte/0, MUL879856-7084,00-MINISSERIE+CAPITU+VAI+APRESENTAR+AN GELINA+JOLIE+BRASILEIRA.html. Acesso em: 19 dez. 2014.

MERTEN, L. C. "Ópera rock desconcerta pelo que tem de excessivo". O Estado de S. Paulo, São Paulo, dez. 2008. Disponível em: http://cultura.estadao.com. br/noticias/artes,opera-rock-desconcerta-pelo-que-tem-de-excessivo,294434. Acesso em: 19 dez. 2014.

MONTEIRO, A. de A. Capitu: olhares para uma narração oblíqua. Dissertação (Mestrado). Universidade Federal da Paraíba, João Pessoa, 2013. Disponível em: 
http://bdtd.biblioteca.ufpb.br/tde_arquivos/9/TDE-2013-10-10T122541Z-2128/ Publico/ArquivoTotal.pdf. Acesso em: 18 dez. 2014.

O GLOBO. "Minissérie Capitu alcança 17 pontos de média no Ibope na estréia". O Globo, Rio de Janeiro, dez. 2008. Disponível em http://oglobo.globo.com/ cultura/revista-da-tv/minisserie-capitu-alcanca-17-pontos-de-media-no-ibopena-estreia-3603924. Acesso em: 19 dez. 2014.

ORICCHIO, L. Z. "Olhos de cigana oblíquos e dissimulados, olhos de ressaca...". O Estado de S. Paulo, São Paulo, jul. 2009. Disponível em http://www. diariodecuiaba.com.br/detalhe.php?cod=335245. Acesso em: 18 dez. 2014.

XAVIER, I. "Do texto ao filme: a trama, a cena e a construção do olhar no cinema". In: PELLEGRINI, T. et al. Literatura, cinema, televisão. São Paulo: Senac, Instituto Itaú Cultural, 2003.

PUCCI, R. "Adaptação televisiva e esquemas cognitivos: o caso de Capitu".

O Estado de São Paulo, São Paulo, dez. 2008. Disponível em: http:// forumdacultura.blogspot.com.br/2008/12/capitu-brecht-bentinho-e-janisjoplin.html. Acesso em: 18 dez. 2014.

STAM, R. Bakhtin: da teoria literária à cultura de massa. São Paulo: Editora Ática, 1992.

STAM, R. "Teoria e prática da adaptação: da fidelidade à intertextualidade". In: CORSEUIL, A. R. (Ed.). Ilha do desterro: Film Beyond Boundaries. Florianópolis: UFSC, 2006. 